\title{
O PERFIL DE FORMAÇÃO DE PROFESSORES DA EDUCAÇÃO PROFISSIONAL QUE ATUAM EM INSTITUIÇÕES PRIVADAS NO RN: uma análise a partir das vozes dos docentes do eixo geral
}

\author{
S. Y. de PAIVA * , D. S. DE B. CORREIA e A. C. BATISTA \\ Instituto Federal de Educação, Ciência e Tecnologia do Rio Grande de Norte \\ samara.paiva@ifrn.edu.br, daniela.bessa@hotmail.com e anacris18 batista@yahoo.com.br
}

Artigo submetido em $x x x x / 20 x x$ e aceito em $x x x x / 20 x x$

DOI: $10.15628 /$ rbept.2017.5784

\section{RESUMO}

Este estudo tem por objetivo analisar o perfil de formação de professores de disciplinas do eixo geral de duas instituições que ofertam cursos de Educação Profissional subsequente ao ensino médio na área de saúde no Rio Grande do Norte. A metodologia caracterizou-se por uma pesquisa empírica que utilizou como técnica de coleta de dados a entrevista semiestruturada. Para as discussões foram utilizados como referências principais as investigações de Moura (2013, 2014), Araujo (2008) e Machado (2008). Os resultados do estudo permitiram apontar para um perfil de formação bastante variado quando tratamos dos profissionais docentes que trabalham na Educação Profissional. Apontamos também que os saberes inerentes à Educação Profissional não são mencionados no percurso formativo dos professores investigados, tampouco são reconhecidos como importantes. Pudemos inferir que os conhecimentos relativos à compreensão do funcionamento da sociedade e das relações entre trabalho, cultura, ciência e Estado, das políticas públicas e dessas, articuladas à educação profissional, além de não serem contempladas na formação inicial dos professores investigados também não constituem objeto de estudo na formação continuada promovida pelas instituições. Por fim, acreditamos que a fragilidade no percurso formativo dos professores se dá pela ausência de políticas públicas de formação inicial e continuada que considere as especificidades e características deste campo da educação.

PALAVRAS-CHAVE: Formação docente, Educação Profissional, Saberes docentes.

\section{THE PROFESSION PROFILE OF PROFESSIONAL EDUCATION THAT ACT IN PRIVATE INSTITUTIONS IN THE RN: an analysis from the voices of the teachers of the general axis} \begin{abstract}
This study aims at analyzing the formation profile of teachers of subjects belonging to the general basis of two institutions which offer professional education courses, after high school in the health-care area in Rio Grande do Norte. The methodology was characterized by an empirical research, which used as a data collection technique, the semi-structured interview. For the discussions, the investigations done by Moura (2013, 2014), Araujo (2008) and Machado (2008) were used as main references. The results of this work have allowed to point out to a varied enough formation profile when we deal with teachers who work in the professional education field. In addition, we highlight that the knowledge connected to this field is not
\end{abstract}

mentioned in the formative track of the investigated teachers, not even recognized as important. Thus, we could infer that the knowledge related to the comprehension of the working of society and relationships among work, culture, science and state, public policies and these linked to professional education. Besides not being considered in the initial formation of the investigated teachers, public policies do not make up study objects in the continuing formation offered by the institutions either. At last, we believe the weakness in the formative track of teachers is due to the lack of public policies of initial and continuing formation which considers the specificities and characteristics of this education field.

KEYWORDS: teacher's formation, professional education, teaching knowledge. 


\section{APRESENTAÇÃO}

No Brasil, o ensino técnico foi institucionalizado em 1909, com a criação de 19 Escolas de Aprendizes e Artífices e o estabelecimento da Rede federal de Educação Profissional e Tecnológica. Apesar de mais de cem anos da oficialização dessa modalidade de ensino, não observamos políticas públicas consistentes e contínuas para formação de professores de seus quadros de docentes (MACHADO, 2008).

Em decorrência da realidade posta, verifica-se, na Educação Profissional (EP), a atuação de docentes leigos quanto aos aspectos didáticos pedagógicos, como também aos aspectos relacionados à própria modalidade de ensino (MACHADO, 2008). Assim, a docência na EP vem sendo, historicamente, ocupada por técnicos, engenheiros e, mais recentemente, por tecnólogos que têm, muitas vezes, sua primeira atuação profissional no magistério em cursos técnicos sem, no entanto, terem contato com os saberes pedagógicos necessários à atuação docente e/ou com essa modalidade de ensino durante sua formação acadêmica.

Nesse cenário, há que se considerar ainda que a educação profissional de nível técnico pode ser oferecida por instituições públicas ou privadas de educação e nas modalidades integrada, subsequente ou concomitante, o que torna maior ainda o desafio da formação de professores para a EP, visto que cada tipo de instituição e/ou de modalidade têm seu papel e seus objetivos dentro da educação, da preparação para o mundo do trabalho e para a vida. Portanto, verifica-se a importância de estudos com esta temática, em primeiro lugar, sob a justificativa da formação de professores na EP deixar de ser "uma ilustre desconhecida" na produção do conhecimento em educação no Brasil e, em segundo, poder gerar subsídios para proposições de políticas publicas sólidas na área.

Diante dessas perspectivas, este trabalho tem como ponto de partida os seguintes questionamentos: Qual o perfil formativo dos professores que atuam na educação profissional técnica de nível médio? Em algum momento do itinerário formativo desses docentes a Educação Profissional foi discutida? A instituição em que esses professores atuam proporciona situações de educação continuada para discutir as práticas docentes e/ou o processo de ensino e aprendizagem na Educação Profissional?

Diante destas indagações, este trabalho tem por objetivo analisar o perfil de formação de professores de disciplinas do eixo geral de duas instituições que ofertam cursos de educação profissional subsequente ao ensino médio na área de saúde no Rio Grande do Norte. Pretendemos, especificamente, identificar o seu perfil de formação e de atuação profissional; analisar a presença ou não da discussão sobre a educação profissional no percurso formativo desses sujeitos e discutir aspectos da formação continuada oferecida pela instituição de atuação dos professores no que se refere às práticas docentes na EP.

\section{MARCOS REGULAMENTADORES DA FORMAÇÃO DE PROFESSORES PARA A EDUCAÇÃO PROFISSIONAL NO BRASIL}

Historicamente, a formação de professores para a educação profissional (EP) no Brasil traz imbricada a marca da descontinuidade. Machado (2008) alerta para a tendência recorrente nos 
documentos oficiais de adjetivação dos cursos de formação de professores para a EP utilizando terminologias como apropriado, especial e emergencial. A autora adverte que "a falta de concepções teóricas consistentes e de políticas públicas amplas e contínuas tem caracterizado, historicamente, as iniciativas de formação de docentes especificamente para a educação profissional, no Brasil." (MACHADO, 2008, p.12).

Peterossi (1994, p. 69) salienta que, se voltarmos a atenção para a formação de professores para esse campo do ensino encontraremos, “[...] muito mais do que uma história de sua formação encontra-se uma trajetória de não-formação no sentido de que, a rigor, nunca houve uma proposta realmente consistente em relação a esses professores."

Uma das primeiras tentativas de formação docente para o ensino na educação profissional foi a criação da Escola Normal de Artes e Ofícios Wenceslau Brás, em 1917, no Rio de Janeiro. Já em 1937, a escola foi fechada e formou apenas 381 professores, em sua grande maioria para atividades de trabalhos manuais em escolas primárias. Poucos, apenas 70 , se formaram como professores, mestres e contramestres para escolas profissionais (MACHADO, 2013; CUNHA, 2000).

Em janeiro de 1946, foi criada a Comissão Brasileiro-Americana de Educação Industrial (CBAI), obedecendo a um acordo firmado entre Brasil, por intermédio do Ministério da Educação e Cultura, e Estados Unidos da América (EUA), por meio do Institute of Inter-American Affairs. Os cursos oferecidos por ocasião desse acordo usavam metodologias de ensino e supervisão de tarefas baseadas nas Séries Metódicas Ocupacionais (SMO), em que "As tarefas consideradas típicas de cada ofício eram decompostas em operações simples, compreendendo quatro fases, a saber: estudo de tarefa, demonstração das operações novas, execução da tarefa pelo educando e avaliação. (CUNHA, 2000, p.132).

A Lei de Diretrizes e Bases da Educação (LDB), Lei $n^{\circ} 4.024 / 1961$, em seu artigo 59, estabeleceu dois caminhos para a formação de professores no Brasil: nas faculdades de filosofia, ciências e letras, para os professores que iriam lecionar o ensino médio e em "Cursos Especiais de Formação Técnica" aos que se habilitassem para lecionar as disciplinas de ensino técnico, se somando à formação técnica desse professor, fosse ela de nível médio ou superior. (MACHADO, 2008).

Em 1968 a Lei $n^{\circ}$ 5.540/68, chamada de reforma universitária, determinou que a formação de todos os professores do ensino de segundo grau, tanto para disciplinas gerais quanto técnicas, deveria acontecer em nível superior. Um prazo de cinco anos foi firmado para a regularização da situação dos não diplomados que já ministravam disciplinas específicas de ensino técnico ou que exerciam funções de administração e de especialistas no ensino primário, para se adequarem à exigência. Porém, na prática, essa exigência não foi atendida. (MACHADO, 2008)

Em 1970, foi criado o Centro Nacional de Aperfeiçoamento de Pessoal para Formação Profissional (CENAFOR), ligado ao MEC e encarregado de preparar e aperfeiçoar professores técnicos e especialistas em educação profissional, bem como prestar assistência técnica para a melhoria e a expansão dos órgãos de formação e aperfeiçoamento de pessoal.

No ano seguinte, um plano integrado de formação de professores de disciplinas específicas de Ensino Médio Técnico foi proposto por meio da Portaria $n^{\circ} 432$. A partir daí, os cursos de caráter emergencial foram desenhados e receberam as denominações de Esquema I e 
Esquema II. O primeiro destinado à complementação pedagógica para portadores de diploma de nível superior. O segundo para aqueles que possuíam diploma em nível técnico. O Esquema I incluía apenas disciplinas de cunho pedagógico e o Esquema II, além das disciplinas de cunho pedagógico, incluía disciplinas de conteúdo técnico específico. (MACHADO, 2008).

No ano de 1977, o Conselho Federal de Educação (CFE) instituiu uma licenciatura plena com vistas à formação de professores para o segundo grau, por meio da Resolução $n^{\circ} 3$, fixando currículo mínimo e determinando que as instituições ofertantes dos esquemas I e II os transformassem em licenciaturas num prazo máximo de três anos. Porém, afirma machado (2008), o esquema I permaneceu admitido em regiões onde a falta de recursos humanos não permitiu a implementação da Licenciatura.

$\mathrm{Na}$ verdade, pouco foi feito com relação à generalização da implantação desse curso. $\mathrm{Na}$ prática, os esquemas I e II continuaram em vigor, pois o CFE continuou emitindo pareceres sobre registros de professores oriundos desses esquemas. Deste modo, em 1982, o parecer que exigia a formação em licenciatura plena para professores do segundo grau foi relaxado, tornando essa formação opcional.

Pouco tempo após o relaxamento da exigência da licenciatura plena para professores do segundo grau, houve uma extinção dos órgãos dedicados à formação docente para o ensino técnico vinculados ao MEC. Suas responsabilidades transferiram-se para a Secretaria de Ensino de Segundo Grau (SESG) do mesmo Ministério, que instituiu um Grupo de Trabalho para discutir e elaborar propostas de cursos regulares de licenciatura plena em matemática específicas do ensino técnico industrial de segundo grau. Uma proposta foi encaminhada, em 1989, ao CFE. Após elaborar parecer, em 1991, o Conselho sugeriu um reexame da legislação pertinente; maior flexibilidade e melhor compatibilidade entre os textos legais que tratam do assunto. Porém, a discussão mais geral sobre a nova LBD ocupou os debates sobre a educação na época, sobrando pouco ou nenhum espaço para discussões sobre o assunto.

Já no ano de 1996, a nova LDB foi sancionada sem trazer explicitações sobre a formação docente para a Educação Profissional e Tecnológica. A regulamentação da Lei foi feita por meio do Decreto 2.208/97 que também não se mostrou muito preocupado com a questão. Na realidade, em alguns pontos, trouxe um retrocesso com relação a dispositivos anteriores sobre formação docente para a EP. Sobre isso, Machado (2008 p. 13-14) afirma:

\footnotetext{
O Decreto no 2.208/97, que veio regulamentar os artigos da nova LDB referentes à educação profissional, interpretou, no seu artigo 90, que as disciplinas do ensino técnico poderiam ser ministradas não apenas por professores, mas por instrutores e monitores, uma incúria com relação às exigências de habilitação docente. Previa que estes deveriam ser selecionados, principalmente, pela experiência profissional, que a preparação para o magistério não precisaria ser prévia, pois poderia se dar em serviço e manteve a admissão de programas especiais de formação pedagógica. Apesar disso, cursos regulares de licenciatura foram também citados, mas sem quaisquer outras referências mais concretas.
}

A autora continua afirmando que é clara "a intenção de valorizar a dimensão da experiência prática em detrimento de uma formação teórica e pedagógica mais consistente" (MACHADO, 2013, p. 360). Esse viés foi sempre predominante na formação docente para a EP e gera um entendimento de que a experiência de viés prático é superior e suficiente para ser professor dessa área da educação. 
A formação docente para a EP, por intermédio de programas especiais, foi disposta na Resolução $\mathrm{n}^{\circ} 2$ do mesmo Decreto. Nela foram instituídos cursos com carga horária total mínima de 540 horas, com 300 horas no mínimo para a prática profissional, e a possibilidade de parte da formação teórica ser oferecida na modalidade à distância. Tais cursos são destinados a diplomados em nível superior e devem se relacionar à habilitação pretendida, enfatizar a metodologia de ensino específica a ela, concedendo direito a certificado e registro profissional equivalentes à licenciatura plena. Com isso, podemos perceber nitidamente a tendência de pouca valorização da formação teórica e que a discussão sobre uma licenciatura plena para essa área foi posta de lado, visto que o Programa Especial de Formação daria Certificação em equivalência à licenciatura.

Vários foram os pareceres que o Conselho Nacional de Educação (CNE) emitiu a partir de consultas sobre a resolução que dispôs sobre os programas especiais de formação pedagógica de docentes para a EP. Em especial, falaremos sobre o Parecer CNE/CEB n ${ }^{\circ} 37 / 2002$, elaborado para responder a uma consulta formulada pelo Departamento Nacional de Aprendizagem Industrial sobre a formação e o exercício das atividades de docentes para a educação profissional de nível médio. Em suas considerações preliminares, o documento considera que:

\begin{abstract}
A rigor, a docência para a educação profissional não está completamente regulamentada. Os dispositivos legais e normativos em vigor constituem respaldo suficiente para um entendimento relativamente flexível e adequado às múltiplas e cambiantes necessidades da educação profissional. A LDB oferece a base legal ampla e mínima. As normas sobre licenciatura, inclusive sobre programas especiais de formação pedagógica, que, em linhas gerais destinam-se à educação básica, permitem adequações pertinentes à educação profissional (BRASIL, 2002, p.1).
\end{abstract}

Ainda nas considerações iniciais, o documento afirma que existem dificuldades praticamente intransponíveis com relação à organização de uma licenciatura específica à educação profissional por dois motivos: as áreas produtivas dos setores da economia são numerosas e cambiantes e a demanda das instituições educacionais de ensino técnico, em geral, não comportariam o esforço e o investimento público e privado necessários à implantação desse curso superior.

O mencionado Parecer ainda enumera todas as possibilidades possíveis de formação desses professores:

1. Formação em curso técnico acrescido de graduação em pedagogia;

2. Formação em curso técnico acrescido de licenciatura;

3. Bacharelado fora da área de atuação acrescido de pós-graduação na área de atuação e programa especial de formação pedagógica;

4. Bacharelado acrescido de pós-graduação na área pedagógica;

5. Licenciatura acrescida de cursos e estágios relacionados à área de docência e experiência profissional em empresa.

No ano de 2006, foi aprovado o Parecer CNE/CP $n^{0} 5 / 2006$ que versa sobre as Diretrizes Curriculares Nacionais para Cursos de Formação para a Educação Básica. Nele está previsto que:

Os cursos de Licenciatura destinados à Formação de Professores para os anos finais do ensino fundamental, o ensino médio e da educação profissional de nível médio serão organizados em habilitações especializadas por componente curricular ou abrangentes 
por campo de conhecimentos, conforme indicado nas Diretrizes Curriculares pertinentes. (BRASIL, 2006, p.3)

Ainda em 2006, a Secretaria de Educação Profissional e Tecnológica do MEC instituiu um Grupo de Trabalho - Formação de Professores para a EPT - com o objetivo de diagnosticar e propor alternativas para o enfrentamento da problemática da formação dos professores de disciplinas profissionalizantes

Diante do visível quadro de descontinuidade e do caráter de excepcionalidade conferidos às políticas públicas concernentes à formação de professores da educação profissional, consideramos de extrema importância fomentar a discussão e a pesquisa sobre a temática, além, é claro, de propor soluções para sua superação. Por isso, compreendemos a importância de conhecer o atual cenário da formação de professores para essa área no Brasil, além de traçar um perfil claro de formação dos docentes que já se encontram em efetivo exercício na EP.

\section{PROCEDIMENTOS METODOLÓGICOS}

Com o intuito de atingir os objetivos traçados, a metodologia utilizada caracterizou-se por uma investigação de campo com uma abordagem qualitativa. O método escolhido para realizar a pesquisa foi a entrevista estruturada a partir da elaboração de um roteiro com perguntas abertas e fechadas. Os questionamentos foram aferidos com o auxílio de um gravador e com a autorização prévia dos entrevistados.

$\mathrm{O}$ instrumento de pesquisa contou com três categorias gerais, a saber: percurso formativo para a docência; percepção de trabalho e de trabalho docente; relação teoria e prática na atuação docente. Para este trabalho, especificamente, nos detivemos nas questões relativas ao percurso formativo dos professores, com o intuito geral de traçar um perfil de formação desses profissionais.

O lócus da pesquisa foram duas instituições privadas de ensino profissionalizante de nível médio na modalidade subsequente com reconhecida e consolidada atuação na área da saúde em Natal, capital do Estado do Rio Grande do Norte. No total foram entrevistados 12 docentes dos quais 6 são da área de formação geral e 6 da específicas dos cursos Técnicos em Análises Clínicas, Técnico em Enfermagem e Técnico em Radiologia Médicai', cabendo-nos, aqui, a análise dos dados coletados nas entrevistas dos professores da formação geral.

É importante salientar que a escolha dos lócus de pesquisa se deu a partir da constatação de que, segundo a Sinopse Estatística da Educação Básica 2014 do Instituto Nacional de Estudos e Pesquisas Educacionais Anísio Teixeira (INEP), entre os docentes da educação profissional no ensino médio, a maior parte atua na forma subsequente $(54,78 \%)$, sendo a rede privada dependência administrativa com a qual esses profissionais mantêm vínculo em maior porcentagem (56\%). (BRASIL, 2014).

Outra constatação importante foi notada no momento do levantamento bibliográfico para a consecução do próprio artigo: apesar da maioria de professores da educação profissional estarem vinculados à rede privada de ensino, o que percebemos é que a maioria dos estudos sobre a formação desses profissionais está voltado para a rede federal de educação, majoritariamente para a formação e as práticas pedagógicas de professores dos Institutos Federais. Por isso, destacamos como de extrema importância estudos que abordem a formação de professores da educação profissional que atuam na rede privada de ensino. 
Por fim, para dar voz aos sujeitos, as entrevistas foram transcritas de forma literal e, por questões éticas, os professores serão aqui referidos como professor 1 - PFG1, professor 2 - PFG2, professor 3 - PFG3, professor 4 - PFG4, professor 5 - PFG5 e professor 6 - PFG6 6 .

\section{RESULTADOS E DISCUSSÕES}

De um modo geral, é bastante variado o perfil acadêmico e, por consequência, os saberes e práticas dos profissionais docentes que trabalham na EP. Segundo Moura (2014), são pelo menos quatro os distintos grupos que abrangem os sujeitos da docência na EP: "Os profissionais não graduados que atuam na EP; os bacharéis ou graduados em cursos superiores de tecnologia, mas não licenciados, em exercício na EP; os licenciados em disciplinas da educação básica que atuam na EP; os que ainda se formarão.". (MOURA, 2014, p. 82).

O gráfico 1, a seguir, apresenta visualmente a já referida sinopse estatística da Educação Básica 2014 do INEP indicando a escolarização e/ou o tipo de formação superior dos professores da educação profissional:

Gráfico 1: Escolarização dos professores da EP

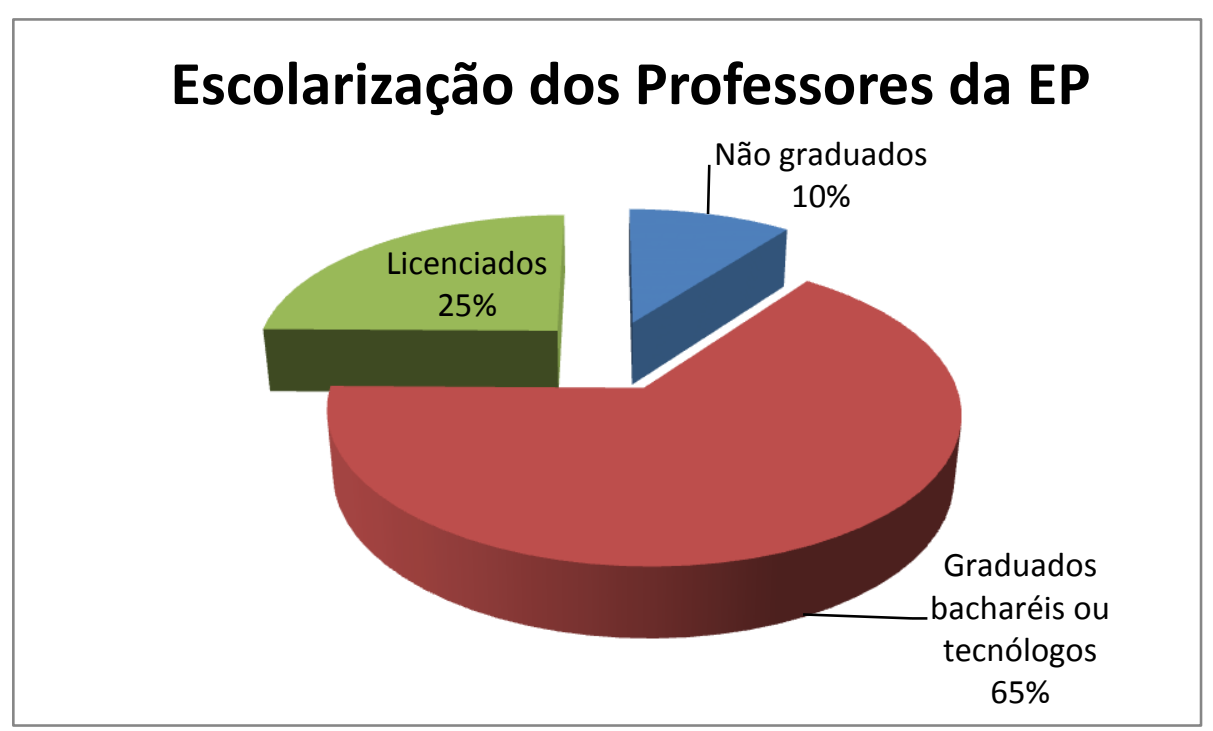

Fonte: Elaboração das autoras, com base na sinopse do INEP (BRASIL, 2014).

No quadro 1 apresentamos o perfil e/ou caracterização formativa dos sujeitos da pesquisa para evidenciar as suas trajetórias de formação, áreas de estudo e de ensino, assim como o tempo de docência na Educação Profissional.

QUADRO 1. Caracterização formativa dos sujeitos da pesquisa

\begin{tabular}{|l|l|l|l|l|}
\hline Sujeito & Formação Superior & Pós-graduação & Disciplina que & Tempo de \\
\hline
\end{tabular}




\begin{tabular}{|c|c|c|c|c|c|}
\hline & & Especialização & Mestrado & leciona & atuação na EP \\
\hline PFG1 & $\begin{array}{l}\text { Licenciatura em } \\
\text { Ciências Biológicas }\end{array}$ & $\begin{array}{l}\text { Vigilância } \\
\text { Sanitária }\end{array}$ & $\begin{array}{l}\text { Bioecologia } \\
\text { aquática }\end{array}$ & $\begin{array}{l}\text { Noções de } \\
\text { pesquisa }\end{array}$ & 13 anos \\
\hline PFG2 & $\begin{array}{l}\text { Licenciatura em } \\
\text { Química }\end{array}$ & - & - & Matemática & 14 anos \\
\hline PFG3 & $\begin{array}{ll}\text { Licenciatura em } \\
\text { História e Direito }\end{array}$ & $\begin{array}{l}\text { Gestão } \\
\text { Educacional }\end{array}$ & - & $\begin{array}{l}\text { Ética, Bioética, } \\
\text { metodologia } \\
\text { da pesquisa e } \\
\text { Direito } \\
\text { Trabalhista }\end{array}$ & 10 anos \\
\hline PFG4 & $\begin{array}{l}\text { Licenciatura em } \\
\text { Ciências Biológicas }\end{array}$ & $\begin{array}{l}\text { Gestão Ambiental } \\
\text { Saúde/IFRN }\end{array}$ & - & $\begin{array}{l}\text { Anatomia e } \\
\text { Fisiologia }\end{array}$ & 03 anos \\
\hline PFG5 & $\begin{array}{ll}\text { Graduação } & \text { em } \\
\text { Enfermagem } & \end{array}$ & - & - & $\begin{array}{l}\text { Disciplinas } \\
\text { gerais do } \\
\text { Módulo CAC }\end{array}$ & 02 anos \\
\hline PFG6 & $\begin{array}{ll}\text { Graduação } & \text { em } \\
\text { Enfermagem } & \end{array}$ & - & - & $\begin{array}{l}\text { Disciplinas } \\
\text { gerais do } \\
\text { Módulo CAC }\end{array}$ & 05 anos \\
\hline
\end{tabular}

Fonte: Elaboração das autoras, a partir das transcrições das entrevistas

No cenário exposto, o percurso formativo dos professores é coerente com o perfil acadêmico de docentes que atuam na Educação Profissional, apresentado por Moura (2014). Nesse caso, investigando os professores que lecionam disciplinas da área geral, prevalecem os licenciados habilitados às disciplinas na Educação Básica sendo também identificado outro perfil que são os profissionais graduados na área especifica em que atuam, mas não licenciados. Porém, evidenciou-se um resultado diferente daquele apontado pelo INEP com relação à formação dos docentes que atuam na EP no Brasil, onde prevalece a atuação dos graduados não licenciados. Uma possível explicação para esse dado pode ser o fato de estarmos lidando com professores que lecionam no eixo geral de cursos na área de saúde que, mesmo sendo na modalidade subsequente, carecem de uma formação basilar de disciplinas como Biologia, Química e Ética.

Diante do perfil de formação apresentado pelos sujeitos da pesquisa, nos interessa, agora, identificar se houveram discussões inerentes à EP no processo formativo desses docentes e, em caso afirmativo, como e em que medida isso ocorreu.

Identificamos nas falas dos professores entrevistados, não haver em seus percursos formativos discussões acerca da EP, tanto na formação inicial, como em cursos posteriores e/ou formação continuada. Quando questionados acerca dessa discussão (EP), em alguns casos, chegam a entender que por lecionarem nas disciplinas da área geral, não há necessidade em sua formação, de saberes inerentes à educação profissional, como percebido no discurso do PFG1: "Até mesmo assim, porque a disciplina que dou no curso profissionalizante ela é mais um complemento para os alunos [...] então ela é um apoio para a vida toda acadêmica do aluno, não tem esse foco.".

As falas nos remetem às reflexões de Oliveira (2006), para confirmar a crença predominante, pelos próprios docentes, de que para ser professor em uma determinada área, satisfaz saber os conhecimentos específicos da sua disciplina. 
Sabemos que o domínio do assunto a ser ensinado com profundidade é condição primordial para o processo de ensino e aprendizagem em qualquer forma de ensino e que o professor necessita ter competência técnica sobre a sua área/disciplina de atuação. Entendemos também que os docentes carecem do domínio dos conhecimentos necessários ao saber ensinar. Porém, destacamos que esses dois tipos de conhecimentos devem estar em diálogo constante entre si e com a sociedade para que uma educação humana e emancipadora, voltada não apenas para o mercado de trabalho, mas para a vida seja realmente alcançada. (MOURA, 2014)

Araujo (2008), referindo-se às especificidades do docente da educação profissional, afirma que:

\begin{abstract}
A docência na educação profissional compreende um saber específico: o conteúdo capaz de instrumentalizar o exercício profissional. A formação do docente da educação profissional deve garantir a articulação dos saberes técnicos específicos de cada área, dos saberes didáticos e do saber do pesquisador.

$[\ldots]$

A estes saberes específicos devem ser incorporados saberes relacionados: a) ao funcionamento da sociedade e das relações entre trabalho, cultura, ciência e Estado; b) às políticas públicas, sobretudo, as educacionais e de educação profissional; c) ao desenvolvimento local e às inovações. (ARAÚJO, 2008, p. 58)
\end{abstract}

Portanto, não basta ter domínio dos conhecimentos específicos da área/disciplina que leciona e dos saberes pedagógicos. Atuar na Educação Profissional exige do docente uma nova concepção de formação que possibilite instrumentalizar seu exercício profissional de forma a "criar situações de aprendizagem nas quais o jovem desenvolva a capacidade de trabalhar intelectualmente, a partir do que se capacita para enfrentar as situações da prática social e do trabalho." (KUENZER, 2008, p.28).

O entrevistado PFG2 afirmou ter discutido a EP no ensino superior:

Sim. Quando eu me formei em química pela [...] foi naquele período que o governo pediu que até 2007 se não me falha a memória, todos professores que estivessem em sala de aula eram para ter nível superior [...]. Porque até então haviam [...]professores que lecionavam, mas só tinham o ensino médio, aquele voltado para a docência e você podia ministrar aula, [...] Então, nesse período que eu ingressei na universidade e ingressei no curso de química, no caso voltado para licenciatura" (PFG2).

Outro professor, neste caso um bacharel, diz não ter a discussão sobre EP em seu percurso formativo, em seguida, pronuncia "mas já na reta final do meu curso na universidade, a gente como enfermeira teve estágio em docência. A gente pode fazer um planejamento de aulas, ministrando algumas aulas em alguns cursos na própria universidade" (PFG5).

Percebemos nessas falas, alguns equívocos relativos à compreensão da Educação Profissional e formação profissional do docente, como estágio e prática de ensino, confirmando o posicionamento de Moura (2013) de que os licenciados, habilitados para exercer a docência em disciplinas na educação básica, não conhecem a $E P$, em virtude de não compor nos currículos das licenciaturas em geral, estudos sobre o campo da educação e do trabalho, bem como acerca da Educação Profissional e "menos ainda sobre a sua relação como ensino médio, de maneira que os professores têm dificuldades para estabelecer conexões entre sua disciplina específica, as tecnologias, o trabalho e a cultura" (MOURA, 2013, p. 161). 
Com a finalidade de aprofundar a investigação acerca do percurso formativo dos professores, o nosso terceiro objeto de estudo é a formação continuada dos professores como espaço/tempo de discussão de práticas docentes e/ou do processo de ensino e aprendizagem na Educação Profissional proporcionada pelas instituições em que atuam.

Conforme disposto nas Diretrizes Curriculares Nacionais para a formação inicial e para formação continuada, (Resolução no 2, de 1엉 de julho de 2015, do Conselho Nacional de Educação - CNE), em seu capítulo VI, artigo 16 a:

\begin{abstract}
Formação continuada compreende dimensões coletivas, organizacionais e profissionais, bem como o repensar do processo pedagógico, dos saberes e valores, e envolve atividades de extensão, grupos de estudos, reuniões pedagógicas, cursos, programas e ações para além da formação mínima exigida ao exercício do magistério na educação básica, tendo como principal finalidade a reflexão sobre a prática educacional e a busca de aperfeiçoamento técnico, pedagógico, ético e político do profissional docente. (BRASIL, 2015, p.53).
\end{abstract}

Sendo a formação continuada desta forma definida, percebemos nas falas dos sujeitos que as instituições de ensino de Educação Profissional envolvidas na pesquisa, embora realizem semestralmente encontros e/ou reuniões ditas formativas, priorizam a discussão de questões administrativas, assim como declara um entrevistado:

\begin{abstract}
Na verdade o momento em que a gente se reúne é quando há as reuniões. As reuniões, digamos assim, no início de cada semestre é convocado todos os docentes e repassados os pontos, a qual eles têm né a sua pauta. Quanto à questão da formação [...] é repassado, digamos assim, a necessidade de ser um docente. De como o docente deve se comportar e o que ele precisa [...]fazer até pra conduzir melhor, digamos assim, ééé'..., o andamento daquele semestre. (PFG5).
\end{abstract}

Enfatizando o objetivo das reuniões, outro entrevistado argumenta que nessas reuniões semestrais, que acontecem em um único dia, inclusive com a presença do diretor da escola, as questões tratadas são majoritariamente administrativas (PFG3). O mesmo entrevistado acrescenta:

\begin{abstract}
Como eu disse a você, os planejamentos aqui, eles são mais é, é, tem o plano de aula, os planos de curso, tal, cada um faz o seu plano de aula. Mas aqueles momentos, que eu acho que você quer saber, dos momentos coletivos, né? Não. Há o incentivo da instituição para os professores fazerem outros cursos, se especializar, mas promovido pela instituição, não. Eles dão mais aqui, aquela parte de psicologia, de motivação, de relações interpessoais. Mas essa parte de cursos, apenas eles incentivam que se faça. (PFG3).
\end{abstract}

Um profissional diz haver formação continuada para discutir o processo de ensino e aprendizagem na Educação Profissional, e relata:

A gente sempre tem reunião aonde eles reúnem todos os professores para discutir [...] Cada professor dá o seu depoimento, sua experiência [...] Assim é (pausa) fica mais na parte das disciplinas profissionalizantes mesmo né?! Mas como eu gosto de participar, então assim o que eu vejo eles discutem muito a questão do estágio, pois o aluno aqui vai para o estágio, então justamente essa parte da prática com a teoria. (PFG1).

Pudemos inferir, por intermédio das falas dos sujeitos, que os conhecimentos relativos à compreensão do funcionamento da sociedade e das relações entre trabalho, cultura, ciência e Estado, das políticas públicas e dessas, articuladas à educação profissional, defendidos por Moura 
(2014) e Araujo (2008), além de não serem contempladas na formação inicial dos professores também não constituem objeto de estudo na formação continuada promovida pelas instituições.

Salientamos, finalmente, amparando-nos nas contribuições de Moura (2014), a importância de constituir, no percurso formativo dos professores, saberes inerentes à $E P$, pois esses articulados na prática pedagógica podem ser fundamentais para que os estudantes alcancem autonomia e emancipação, de modo que possam atuar na perspectiva da transformação social orientada ao atendimento dos interesses e necessidades das classes trabalhadoras.

\section{CONSIDERAÇÕES FINAIS}

Neste estudo, ficou evidenciado que o perfil de formação dos professores da Educação Profissional não contempla, em sua maioria, os saberes necessários para o seu exercício da docência neste campo da educação. Uma das explicações para essa carência pode ser a falta de estudos sobre o campo da Educação Profissional nos currículos dos cursos superiores e na formação continuada dos profissionais já na ativa.

Com relação à ausência de discussões sobre a Educação profissional na formação inicial e continuada dos professores, pudemos concluir que é urgente a adoção de estratégias sem o caráter de transitoriedade e precariedade tão presentes quanto tratamos da formação docente para EP. Duas soluções delineiam-se para a formação didático-político-pedagógica dos docentes que ainda não possuem curso de licenciatura: os cursos de licenciatura dirigidos para a EP e a pós-graduação, principalmente, lato sensu. No tocante aos profissionais licenciados, é necessário que o docente tenha uma formação continuada específica que lhe aproxime à problemática das relações entre trabalho e educação e ao campo da educação profissional, colaborando com a integração entre trabalho, ciência, tecnologia e cultura, visto que os cursos de licenciatura, em geral, não abordam estudos sobre esse campo da educação.

Por fim, depreendemos a inexistência quase total de uma formação continuada para os professores que já estão trabalhando na EP, caracterizando uma necessidade imprescindível de incentivo e conscientização desses profissionais e das instituições onde atuam no sentido de maiores investimentos e disponibilidade de momentos para discussão do processo de ensino e aprendizagem na Educação Profissional.

\section{REFERÊNCIAS}

1. ARAUJO, R.M.L. Formação de docentes para a educação profissional e Tecnológica: por uma pedagogia integradora da educação profissional. Trabalho \& Educação. Vol. 7. no 2.mai-/ago, 2008.

2. BRASIL. Ministério da Educação. Instituto Nacional de Estudos e Pesquisas Educacionais Anísio Teixeira. Sinopses Estatísticas da Educação Básica, 2014. Disponível em: <http://portal.inep.gov.br/basica-censo-escolar-sinopse-sinopse>. Acesso em: 08 abr. 2016.

3.

Parecer CNE/CEB no 37, de 4 de setembro de 2002. Consulta sobre formação de professores para a Educação Profissional de Nível Técnico. Disponível em: 
http://portal.mec.gov.br/cne/arquivos/pdf/CEB0037 2002.pdf. Acesso em 08 de abril de 2016.

4. _. Parecer CNE/CP no 02, de 9 de junho de 2015. Diretrizes Curriculares Nacionais para a Formação Inicial e Continuada dos Profissionais do Magistério da Educação Básica. Disponível em: http://portal.mec.gov.br/index.php?option=com docman\&view=download\&alias=17625parecer-cne-cp-2-2015-aprovado-9-junho-2015\&category slug=junho-2015pdf\&Itemid=30192. Acesso em 08 de abril de 2016.

5. ___.Parecer CNE/CP no 05, de 4 de abril de 2006. Aprecia Indicação CNE/CP no 2/2002 sobre Diretrizes Curriculares Nacionais para Cursos de Formação de Professores para a Educação Básica. Disponível em: http://portal.mec.gov.br/cne/arquivos/pdf/pcp005 06.pdf. Acesso em 08 de abril de 2016.

6. CUNHA, L. A. O ensino profissional na irradiação do industrialismo. São Paulo: Editora UNESP, Brasília, DF: Flacso, 2000.

7. KUENZER, A. Formação de professores para a educação profissional e tecnológica: perspectivas históricas e desafios contemporâneos. In: INEP. Formação de Professores para Educação Profissional e Tecnológica: Brasília, 26, 27 e 28 de setembro de 2006. Brasília: Instituto Nacional de Estudos e Pesquisas Educacionais Anísio Teixeira, 2008.

8. MACHADO, L.R.B. de S. Diferenciais inovadores na formação de professores para a educação profissional. Revista Brasileira de educação Profissional e tecnológica. 2008; v. 1, n.1 (jun. 2008): p. $8-22$.

9. MACHADO, L.R.B. de S. Formação de Professores Para a Educação Profissional e Tecnológica: perspectivas históricas e desafios contemporâneos. In: MOURA, D.H (Org.) Produção do conhecimento, Políticas Públicas e Formação Docente em Educação Profissional. Campinas, SP: Mercado de Letras, 2013. p. 347-362.

10. MOURA, D. H. Ensino Médio e Educação Profissional No Brasil nos anos 2000: movimentos contraditórios. In: MOURA, D.H (Org.) Produção do conhecimento, Políticas Públicas e Formação Docente em Educação Profissional. Campinas, SP: Mercado de Letras, 2013. p. 141-200.

11. MOURA, D. H. Trabalho e formação docente na educação profissional. Coleção formação pedagógica. v.3. Curitiba, PR: IFPR -EAD. 2014.

12. OLIVEIRA, M. R. N. S. de. Formação e profissionalização dos professores do ensino técnico. Educação e Tecnologia, Belo horizonte, v. 11, n. 2 p. 3-9, jul./dez. 2006.

13. PETEROSSI, H. G. Formação de professores para o ensino técnico. São Paulo: Edições Loyola, 1994.

\section{NOTAS:}

\footnotetext{
' Vale salientar que a pesquisa aqui analisada fez parte de uma investigação maior em que abordamos professores que lecionam disciplinas de formação geral e formação específica no ensino profissionalizante. Esta investigação foi realizada pela turma de discentes que cursam a disciplina de Formação Docente para a Educação Profissional ofertada no Mestrado em Educação Profissional orientados pelas professoras responsáveis por esse módulo.
} 
ii PFG = Professor da formação Geral.

iii Anatomia I, Fisiologia I, Atendimento Pré- Hospitalar - Humanização, Primeiros Socorros, Psicologia, Políticas de Saúde Pública, Ética e Bioética e Legislação da Saúde. 